\title{
Thiourea-based polyimide/RGO composite cathode: A comprehensive study of storage mechanism with alkali metal ions
}

\author{
Peixun Xiong ${ }^{1}$, Huimin Yin $^{2}$, Zifeng Chen ${ }^{1}$, Chen Zhao ${ }^{1}$, Jixing Yang ${ }^{1}$, Shuping Huang ${ }^{2 *}$ and \\ Yunhua $\mathrm{Xu}^{1,3}$
}

\begin{abstract}
Although organic electrode materials have merits of abundant resources, diverse structures and environmental friendliness, their performance for electrochemical energy storage is far insufficient. In this work, a thiourea-based polyimide/reduced graphene oxide (PNTCSA/ RGO) composite was synthesized via a condensation polymerization method. As a cathode material in lithium-ion batteries, excellent performance is demonstrated with high reversible capacity $\left(144.2 \mathrm{~mA} \mathrm{~h} \mathrm{~g}^{-1}\right)$, high discharge voltage $(\sim 2.5 \mathrm{~V})$, and long cycling life (over 2000 cycles at $500 \mathrm{~mA} \mathrm{~g}^{-1}$ ), which are comparable to those of other well documented inorganic electrodes. Encouraging electrochemical performance is also demonstrated for sodium-ion batteries (a cycling life of 800 cycles at $500 \mathrm{~mA} \mathrm{~g}^{-1}$ ), while poor performance is delivered in potassium-ion batteries. Theoretical studies reveal that the active sites are carbonyl groups for all alkali ions but one inserted alkali metal ion is shared by two carbonyl groups from the two neighbor units. More importantly, $\mathrm{K}$ ions have stronger interaction with $\mathrm{S}$ atoms than $\mathrm{Li} / \mathrm{Na}$ ions, which may lead to poor structure reversibility and account for the poor cycling performance. Our findings provide a fundamental understanding of polyimide-based polymer electrodes and help to design and develop high-performance organic electrode materials for alkali metal ion batteries.
\end{abstract}

Keywords: electrochemical energy storage, polyimide, organic electrode material, lithium/sodium/potassium-ion battery

\section{INTRODUCTION}

Benefiting from the high energy density and long cycle life, lithium-ion batteries (LIBs) are widely used in various applications ranging from portable electronics to electric vehicles $[1,2]$. In addition, sodium-ion batteries (SIBs) and potassium-ion batteries (KIBs) are also regarded as promising candidates for large-scale electrochemical energy storage applications owing to the low cost and resource abundance of $\mathrm{Na}$ and $\mathrm{K}[3,4]$. Over the past decades, numerous efforts have been devoted to developing potential materials for alkali metal (AM, $\mathrm{AM}=\mathrm{Li}, \mathrm{Na}$ and $\mathrm{K}$ ) ion batteries $[1,5,6]$. Nevertheless, conventional AM ion batteries often use inorganic electrode materials such as transition-metal oxides, which usually show high production prices, dependence on scarce natural resources, and environmental issues due to toxicity and pollution $[1,5,6]$. Therefore, exploring advanced electrode materials with low-cost and ecofriendliness are highly desired for mass manufacturing and large-scale application of energy storage.

Organic electrode materials possess great potential for green and sustainable AM ion storage because of their abundance in nature, potential environmental friendliness, and flexible and designable structure [7-14]. Based on the structures of electrochemically active functional groups involved in the redox reactions, different types of organic electrode materials have been reported, including conducting polymers, organosulfur compounds, organic radicals, and carbonyl compounds [8-10]. Among them, carbonyl compounds (quinones, carboxylates, anhy-

\footnotetext{
${ }^{1}$ School of Materials Science and Engineering, Key Laboratory of Advanced Ceramics and Machining Technology (Ministry of Education), and Tianjin Key Laboratory of Composite and Functional Materials, Tianjin University, Tianjin 300072, China

${ }^{2}$ Fujian Provincial Key Laboratory of Electrochemical Energy Storage Materials, College of Chemistry, Fuzhou University, Fuzhou 350108, China

${ }^{3}$ Collaborative Innovation Center of Chemical Science and Engineering (Tianjin), Tianjin 300072, China

* Corresponding authors (emails: yunhua.xu@tju.edu.cn (Xu Y); huangshp@gmail.com (Huang S))
} 
drides, imides, and ketones) are the most widely studied because of their high capacity and electrochemical activity [15]. However, most small-molecule carbonyl compounds suffer from rapid dissolution into organic electrolytes and poor electronic conductivity, leading to insufficient electrochemical performance $[16,17]$.

Various strategies have been developed to tackle these problems, including polymerization, salinization, hybridization with insoluble materials, optimization of electrolyte, and so on [7-17]. As one type of conjugated carbonyl compounds, polyimides (PIs) show rather high capacities and tunable redox potentials. Along with the merit of scalable syntheses, they represent a promising class of redox-active cathode materials for AM ion batteries [18]. In 2010, Zhan's group [19] first used PIs as cathode materials for LIBs and found that the voltage profiles of PIs were associated with the dianhydride components rather than diamine units. Thereafter, Song et al. [20] developed an ethylenediamine-based PI/graphene nanocomposite through a simple in situ polymerization process and achieved high-rate performance for LIBs. Huang and co-workers [21] also constructed a flexible ethylenediamine-based $\mathrm{PI} /$ reduced graphene oxide (RGO) composite, which showed moderate discharge plateau $(\sim 2.30 \mathrm{~V})$ and cycle life $(600$ cycles) in LIBs. Recently, Fan and co-workers [22] reported a PI polymer/carbon nanotube composite and demonstrated excellent cycling performance of over 10,000 cycles in a highly concentrated electrolyte as an LIB cathode but still a low discharged voltage of $\sim 1.8 \mathrm{~V}$. High voltages of $\sim 2.5 \mathrm{~V}$ can be obtained using urea and sulfonyl-based PI cathode materials, but the cycling performance is poor $[23,24]$. A few studies have also attempted to use PI-based cathode materials in SIBs and KIBs, although the performance is insufficient. In addition, the fundamental understanding of the reaction mechanism and the relationship between the molecular structure and the electrochemical behavior has been rarely reported.

Herein, thiourea group-connected 1,4,5,8-naphthalenetetracarboxylic dianhydride (NTCDA)-derived PI/ RGO (PNTCSA/RGO) composite was prepared via a simple condensation polymerization method. The composite can serve as a universal host material for $\mathrm{Li}^{+}, \mathrm{Na}^{+}$, and $\mathrm{K}^{+}$ions and deliver highly reversible storage behavior, demonstrating its supremacy for AM ion batteries. The electrochemical redox behavior was systematically investigated by experimental analyses and theoretical calculations. The results show that the ionic radius of AM ions and the molecular structure of PI synergistically determine the electrochemical performance of the PI cathode materials.

\section{EXPERIMENTAL SECTION}

\section{Syntheses of PNTCSA/RGO and PNTCSA}

In a typical synthesis, NTCDA $(0.268 \mathrm{~g}, 1 \mathrm{mmol})$ and RGO sheets $(0.04 \mathrm{~g})$ were mixed in $\mathrm{N}$-methyl pyrrolidone (NMP, $10 \mathrm{~mL}$ ). The mixture was then sonicated for $30 \mathrm{~min}$. After thiourea $(0.077 \mathrm{~g}, 1 \mathrm{mmol})$ was added into the mixture, the reaction proceeded under stirring and refluxing at $175^{\circ} \mathrm{C}$ under $\mathrm{N}_{2}$ for $15 \mathrm{~h}$. After being cooled down to room temperature, the solid was separated from the mixture and washed with NMP and acetone thrice to remove the soluble oligomer. Then the insoluble solid product was dried under vacuum at $150^{\circ} \mathrm{C}$ for $12 \mathrm{~h}$, and finally annealed at $300^{\circ} \mathrm{C}$ under $\mathrm{N}_{2}$ atmosphere for $8 \mathrm{~h}$. PNTCSA was also synthesized with the similar method for PNTCSA/RGO, except without adding RGO sheets.

\section{Materials characterization}

$\mathrm{X}$-ray diffraction (XRD) patterns were collected on a Rigaku Ultima IV using Cu Ka radiation $(\lambda=1.5406 \AA$, $40 \mathrm{kV}$ and $40 \mathrm{~mA}) \cdot{ }^{13} \mathrm{C}$ NMR spectroscopy was carried out using BrukerAvance 400 nuclear magnetic resonance spectrometers. Fourier transform infrared (FTIR) spectra were recorded by the attenuated total reflectance mode in the range of $4000-400 \mathrm{~cm}^{-1}$ on a BRUKER ALPHA II FTIR Spectrometer. Ultraviolet-visible (UV-vis) spectroscopy measurements were performed on a Shimadzu UV3600 plus. Scanning electron microscopy (SEM, S-4800 instrument) and transmission electron microscopy (TEM, FEI F20 S-TWIN instrument) were applied for the structural characterization of the samples. Themogravimetric analysis (TGA) was carried out using thermogravimetric analyzer (TA Instruments, USA) with a heating rate of $10^{\circ} \mathrm{C} \mathrm{min}^{-1}$ in nitrogen.

\section{Electrochemical measurements}

To prepare electrodes, PNTCSA/RGO was mixed with Super $\mathrm{P}$ and polyvinylidene fluoride (PVDF) binder in a weight ratio of 85:5:10 and dispersed in NMP to form a slurry. For PNTCSA electrodes, PNTCSA was mixed with Super $\mathrm{P}$ and PVDF in a weight ratio of 70:20:10, and then dispersed in NMP to form a slurry. The slurry was then casted onto $\mathrm{Al}$ foils, and vacuum-dried at $120^{\circ} \mathrm{C}$ for $12 \mathrm{~h}$. The mass loading of the active material was about $0.8-1.0 \mathrm{mg} \mathrm{cm}^{-2}$. R2032-type coil cells were assembled in a glove box filled with highly pure argon gas $\left(\mathrm{O}_{2}\right.$ and $\mathrm{H}_{2} \mathrm{O}$ levels $<0.1 \mathrm{ppm})$. Lithium, sodium, and potassium metal (Sigma Ltd) was used as counter electrodes. The separator 
was Celgard2400 (Celgard, LLC Corp., USA). The electrolytes were $1 \mathrm{~mol} \mathrm{~L}^{-1}$ lithium bis(trifluoromethanesulphonyl)imide (LiTFSI) in 1,2-dimethoxyethane (DME) for LIBs, $1 \mathrm{~mol} \mathrm{~L}^{-1}$ sodium hexafluorophosphate (NaPF6) in DME for SIBs, and $1 \mathrm{~mol} \mathrm{~L}^{-1}$ potassium bis(trifluoromethanesulphonyl)imide (KTFSI) in DME for KIBs, respectively. Galvanostatic charge/discharge tests were performed in a voltage range of 1.5 to $3.5 \mathrm{~V}$ at different current densities on a LAND Battery Testing system (CT-2001A). Cyclic voltammetry (CV) was performed on an electrochemistry workstation (CHI660E).

\section{Computational methods and details}

All calculations were performed by using Gaussian 09 program [25]. Geometrical optimizations were carried out by B3LYP density functional. All atoms adopted the 6-31G (d, p) basis sets [26]. The Multiwfn program was used to observe the volume changes [27]. We also defined the averaged binding energy $\Delta E$ of the AM-PNTCSA (AM stands for $\mathrm{Li}, \mathrm{Na}, \mathrm{K}$ ) complex as

$\Delta E=\frac{E_{\mathrm{tot}}\left(\mathrm{AM}_{x}-\mathrm{PNTCSA}\right)-E_{0}(\mathrm{PNTCSA})-x E_{\mathrm{AM}}}{x}$,

where $E_{\text {tot }}\left(\mathrm{AM}_{x}-\mathrm{PNTCSA}\right)$ and $E_{0}(\mathrm{PNTCSA})$ represent the total energy of the $\mathrm{AM}_{x}$-PNTCSA complex with $x$ alkali-metal ions and the original energy of PNTCSA, respectively. And $E_{\mathrm{AM}}$ is the energy of a free AM atom.

\section{RESULTS AND DISCUSSION}

The electrochemical performance of NTCDA-based PI materials is intimately related to their electronic structures. In this work, the electronic structures of PNTCNA, urea-based PI (PNTCOA), PNTCSA, and NTCDA were studied by density functional theory (DFT) calculation (Fig. 1). On the basis of molecular orbital theory, the lowest unoccupied molecular orbital (LUMO) energy is related to the electron affinity, which determines the voltages of PI-based electrode materials [19]. Although NTCDA shows the lowest LUMO energy level, it suffers from severe dissolution in organic liquid electrolytes, which makes it unsuitable as an electrode material. PNTCNA, PNTCOA and PNTCSA exhibit slightly higher LUMO energy levels than NTCDA, predicting lower voltages in batteries, but have a poor dissolution in organic liquid electrolytes. It is noteworthy that PNTCSA has a smaller band gap $\left(E_{\mathrm{g}}\right)$ between the highest occupied molecular orbital (HOMO) and LUMO energy levels, which could increase the electronic conductivity, thus promising a better electrochemical performance as a cathode material in AM ion batteries.

PNTCSA was synthesized via a high temperature condensation reaction of NTCDA and thiourea in an NMP solution (Fig. 2a). PNTCSA/RGO composite was also synthesized with the similar method as PNTCSA, except with RGO sheets added in the reaction solution. XRD

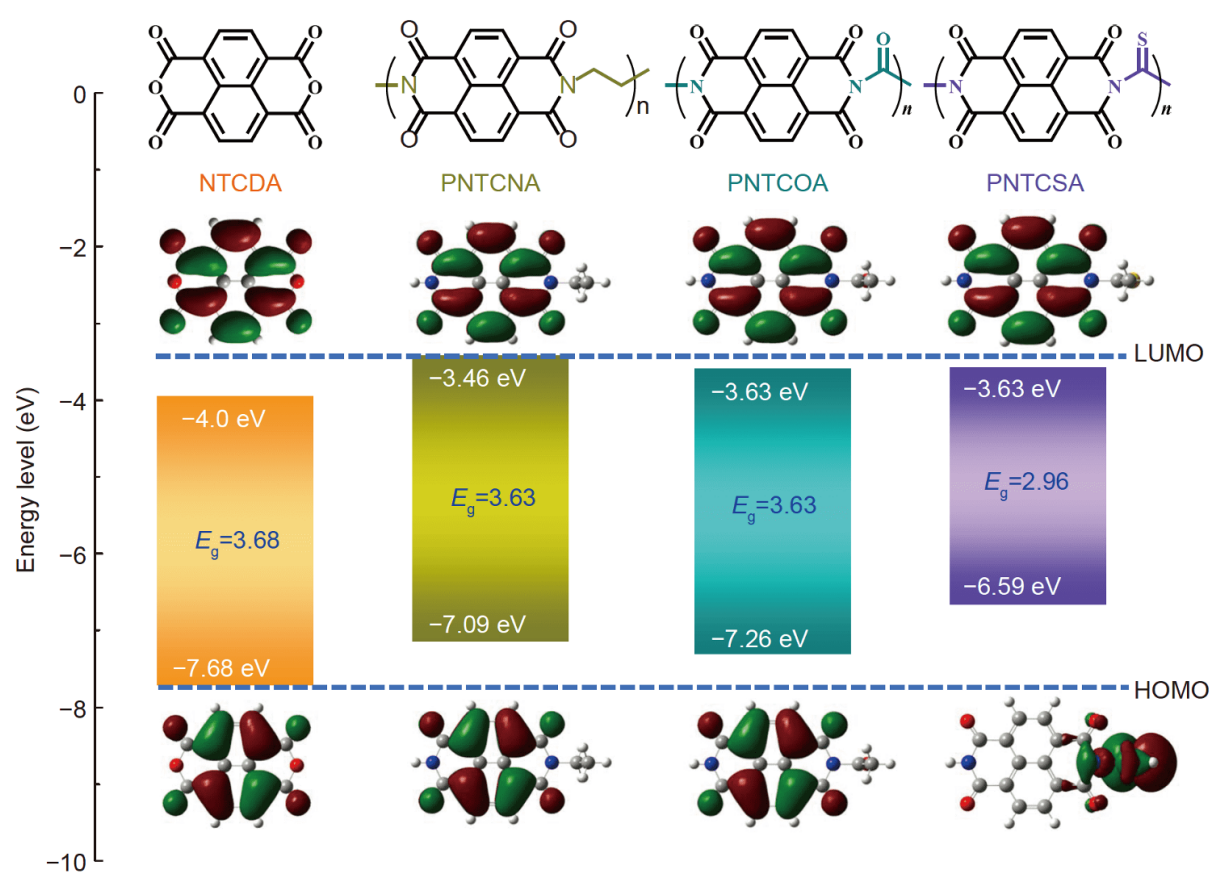

Figure 1 Molecular structures, HOMO/LUMO energy levels and orbit distributions of NTCDA, PNTCNA, PNTCOA and PNTCSA. 

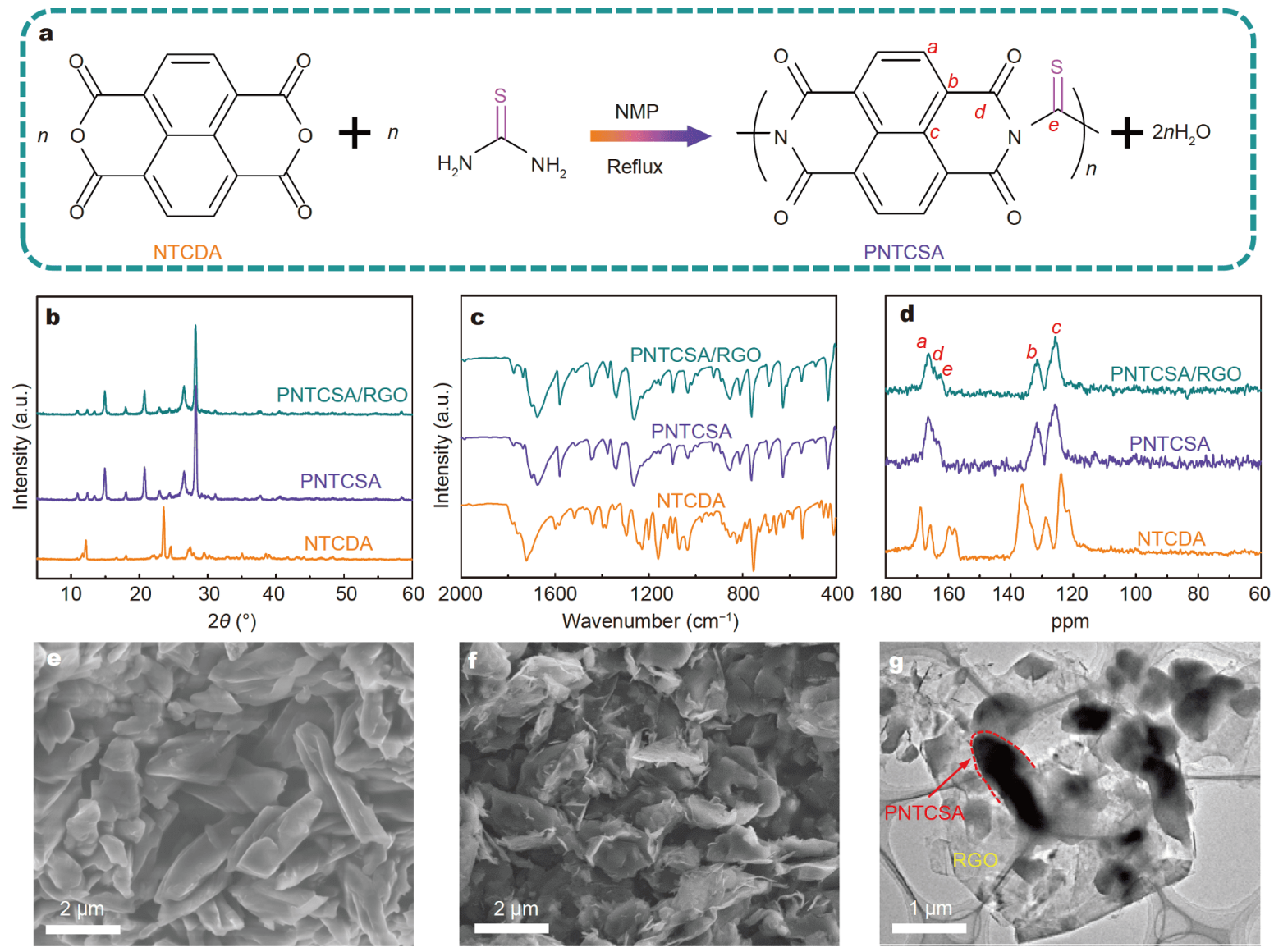

Figure 2 (a) Synthetic route of PNTCSA. (b) XRD patterns, (c) FTIR spectra and (d) ${ }^{13} \mathrm{C}$ solid state NMR spectra of NTCDA, PNTCSA and PNTCSA/RGO. (e) SEM image of PNTCSA. (f) SEM and (g) TEM images of PNTCSA/RGO.

patterns of NTCDA, PNTCSA and PNTCSA/RGO composite show a well-crystalline nature, which are different from that of PNTCNA (Fig. 2b) [21]. The structures of PNTCSA and PNTCSA/RGO composite were characterized by FTIR and ${ }^{13} \mathrm{C}-\mathrm{NMR}$ spectroscopy. The FTIR spectra show a peak shift of $\mathrm{C}=\mathrm{O}$ vibration from $1780-1720 \mathrm{~cm}^{-1}$ for NTCDA to 1696 and $1667 \mathrm{~cm}^{-1}$ for PNTCSA/RGO and PNTCSA (Fig. 2c), suggesting the conversion of anhydride groups to imide groups [28]. Two new vibration peaks at 1340 and $1261 \mathrm{~cm}^{-1}$ are attributed to the stretch of $\mathrm{C}-\mathrm{N}$ and $\mathrm{C}=\mathrm{S}$ groups, respectively [29]. The ${ }^{13} \mathrm{C}$-NMR spectra of PNTCSA/RGO and PNTCSA display a peak at $\sim 162 \mathrm{ppm}$, assigned to $\mathrm{C}=\mathrm{S}$ bond of imide ring (Fig. 2d), and the peaks at 166.5, 131.5 , and $121.6 \mathrm{ppm}$ are attributed to $\mathrm{C}$ atoms in naphthalene structure with a systematic shift [30]. These results indicate that NTCDA is successfully polymerized with thiourea. The solubility of NTCDA, PNTCSA and PNTCSA/RGO in electrolytes was investigated by immersing them in DME and soaking for one day. The supernatants of the soaked solvents were analyzed by UVvis spectroscopy (Fig. S1). No obvious absorption signal was detected for PNTCSA and PNTCSA/RGO, while NTCDA shows strong absorption peak, demonstrating a low solubility of PNTCSA in the solvent that is used in electrolytes.

The morphology of pure PNTCSA and PNTCSA/RGO composite were examined by SEM and TEM. The SEM image shows that pure PNTCSA has a random particle morphology with a size of $\sim 2 \mu \mathrm{m}$. In contrast, PNTCSA/ RGO displays a much smaller particle size of $\sim 1 \mu \mathrm{m}$, with uniform dispersion in the RGO matrix (Fig. 2e-g and Fig. S2). This would enable a short diffusion distance and fast kinetics, and help accommodate volume change during $\mathrm{AM}$ ion insertion/extraction. TGA reveals that PNTCSA/RGO has a much higher decomposition temperature $\left(\sim 352^{\circ} \mathrm{C}\right)$ than PNTCSA $\left(\sim 284^{\circ} \mathrm{C}\right)$, showing that PNTCSA/RGO is more thermally stable than PNTCSA (Fig. S3). This also contributes to a stable electrochemical performance. RGO weight percentage was calculated to 
be $31.3 \%$.

The lithium ion storage performance of PNTCSA/RGO and PNTCSA was investigated in half coin cells using lithium as counter electrodes and $1.0 \mathrm{~mol} \mathrm{~L}^{-1}$ LiTFSI in DME as the electrolyte. Fig. 3a, b show the CV curves of the PNTCSA/RGO and PNTCSA cathodes. One pronounced cathodic peak is observed at $\sim 2.4 \mathrm{~V}$, while two well-defined anodic peaks are displayed, indicating a twoelectron reaction for each imide unit. The well overlapped $\mathrm{CV}$ curves in the selected cycles show a good stability of the PNTCSA/RGO and PNTCSA cathodes. Fig. 3c, d present the charge/discharge voltage profiles of PNTCSA/ RGO and PNTCSA in the selected cycles, respectively. Both of them display a flat discharge plateau at $\sim 2.5 \mathrm{~V}$, which is in good agreement with the CV curves (Fig. 3a, b). The flat discharge plateau would help to deliver a stable output voltage. This is different from other re- ported PIs that present sloping voltage profiles. In addition, the discharge plateau of PNTCSA/RGO is higher than that of the ethylenediamine-based PIs ( $\leq 2.3 \mathrm{~V})[20]$, which is attributed to the electron-withdrawing nature of the $\mathrm{C}=\mathrm{S}$ bond that reduces the electron density of the redox-active carbonyl. The PNTCSA/RGO composite delivers an initial discharge capacity of $146 \mathrm{~mA} \mathrm{~h} \mathrm{~g}^{-1}$ and a charge capacity of $144.2 \mathrm{~mA} \mathrm{~h} \mathrm{~g}^{-1}$ based on the mass of PNTCSA, corresponding to a coulombic efficiency (CE) of $98.8 \%$. The capacity contribution of RGO to the total capacity of the composite has been deducted (Fig. S4).

Good rate performance was achieved for PNTCSA/ RGO. As shown in Fig. 3e, the average reversible capacities are 161.6, 150.1, 139.4, 123.3, 111.5, and $102.8 \mathrm{~mA} \mathrm{~h} \mathrm{~g}^{-1}$ at current densities of 50, 100, 200, 500, 800 , and $1000 \mathrm{~mA} \mathrm{~g}^{-1}$, respectively. When the current density is switched back to $100 \mathrm{~mA} \mathrm{~g}^{-1}$, a high capacity of
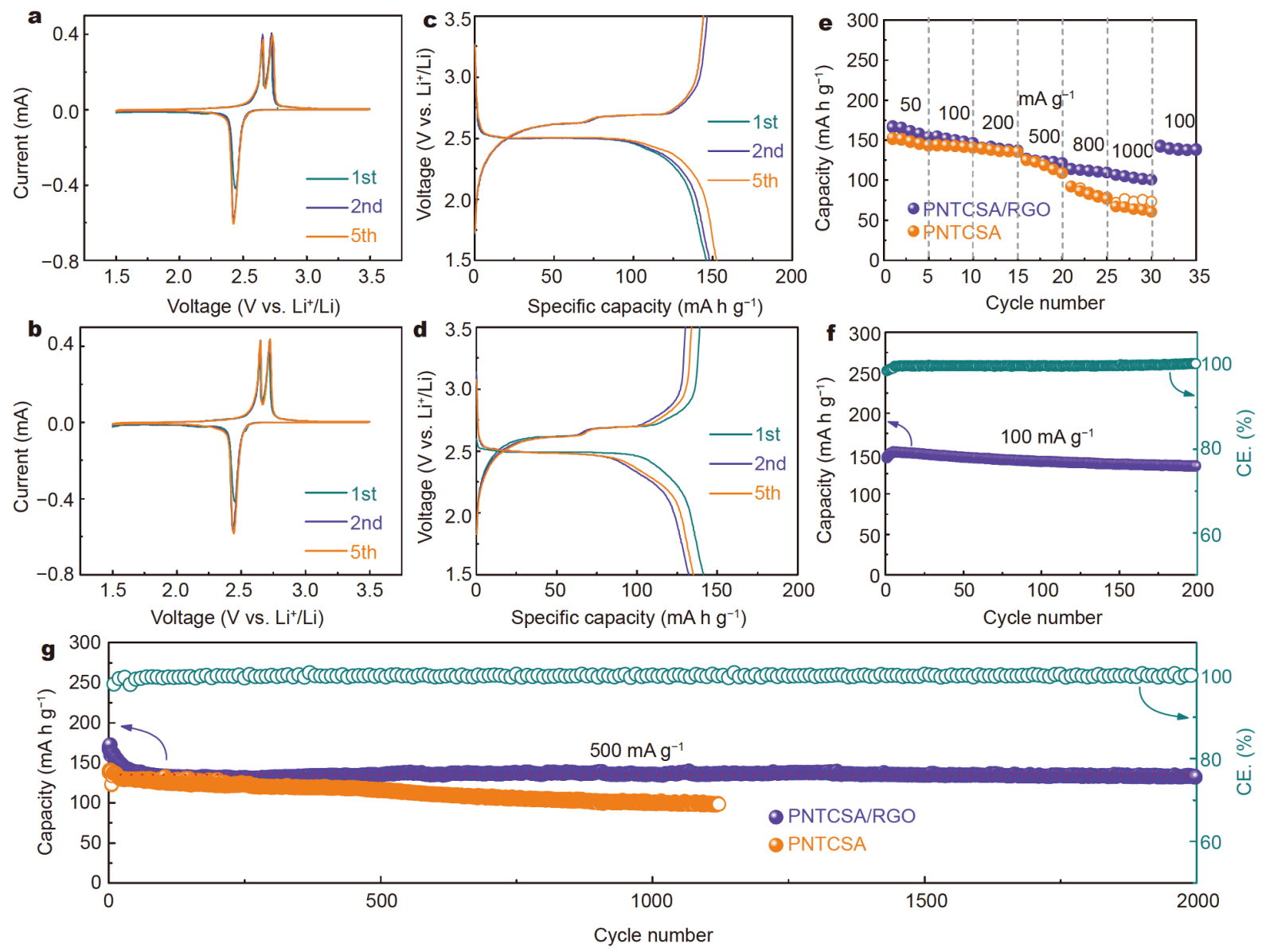

Figure 3 Electrochemical performances of the PNTCSA/RGO and PNTCSA cathodes in LIBs. CV curves of (a) PNTCSA/RGO and (b) PNTCSA at $0.05 \mathrm{mV} \mathrm{s}^{-1}$. Galvanostatic discharge-charge profiles of (c) PNTCSA/RGO and (d) PNTCSA at $100 \mathrm{~mA} \mathrm{~g}^{-1}$. (e) Rate performance at different current densities. (f) Cycling performance and CE of PNTCSA/RGO at $100 \mathrm{~mA} \mathrm{~g}^{-1}$. (g) Long-term cycling performance and CE at $500 \mathrm{~mA} \mathrm{~g}^{-1}$ (the electrodes were activated at $100 \mathrm{~mA} \mathrm{~g}^{-1}$ for 3 cycles). 
$137.6 \mathrm{~mA} \mathrm{~h} \mathrm{~g}^{-1}$ is recovered, and stable discharge plateaus are observed at different current densities, demonstrating a good sustainability and rate capability (Fig. S5). In comparison, PNTCSA delivers a worse rate performance with relatively low capacities at increased current densities (Fig. 3e). The cycling performance of PNTCSA/ RGO is first evaluated at $100 \mathrm{~mA} \mathrm{~g}^{-1}$ (Fig. 3f). A high capacity of $133.8 \mathrm{~mA} \mathrm{~h} \mathrm{~g}^{-1}$ remains after 200 cycles. Even at a high mass loading of $\sim 3.1 \mathrm{mg} \mathrm{cm}^{-2}$, the PNTCSA/ RGO composite still delivers a stable cycling performance with a high capacity retention of $143.3 \mathrm{~mA} \mathrm{~h} \mathrm{~g}^{-1}$ after 100 cycles at $100 \mathrm{~mA} \mathrm{~g}^{-1}$ (Fig. S6). The long-term cycling performance is examined at $500 \mathrm{~mA} \mathrm{~g}^{-1}$, and there is no capacity decay from the $100^{\text {th }}$ to the $2000^{\text {th }}$ cycle (Fig. $3 \mathrm{~g}$ ), demonstrating an excellent cycling performance. CE approaches $100 \%$ after 100 cycles. In contrast, pure
PNTCSA shows a worse stability with the capacity retention of only $97 \mathrm{~mA} \mathrm{~h} \mathrm{~g}^{-1}$ after 1100 cycles. Such excellent cycling performance and high discharge voltage of PNTCSA/RGO composite is superior to most reported PI cathodes for LIBs (Table S1). Apparently, the enhanced electrochemical performance is at least partially associated with the introduction of RGO, which not only makes a smaller particle size of PNTCSA but also enables uniform distribution.

Sodium and potassium storage performance of PNTCSA/RGO was also evaluated in coin cells (Fig. 4). SIBs and KIBs were assembled by paring PNTCSA/RGO cathodes with metal sodium and potassium foils and electrolytes of $1 \mathrm{~mol} \mathrm{~L}^{-1} \mathrm{NaPF}_{6}$ and $1 \mathrm{~mol} \mathrm{~L}^{-1} \mathrm{KTFSI}$ in DME, respectively. CV tests of PNTCSA/RGO cathodes in SIBs and KIBs were conducted at a scan rate of
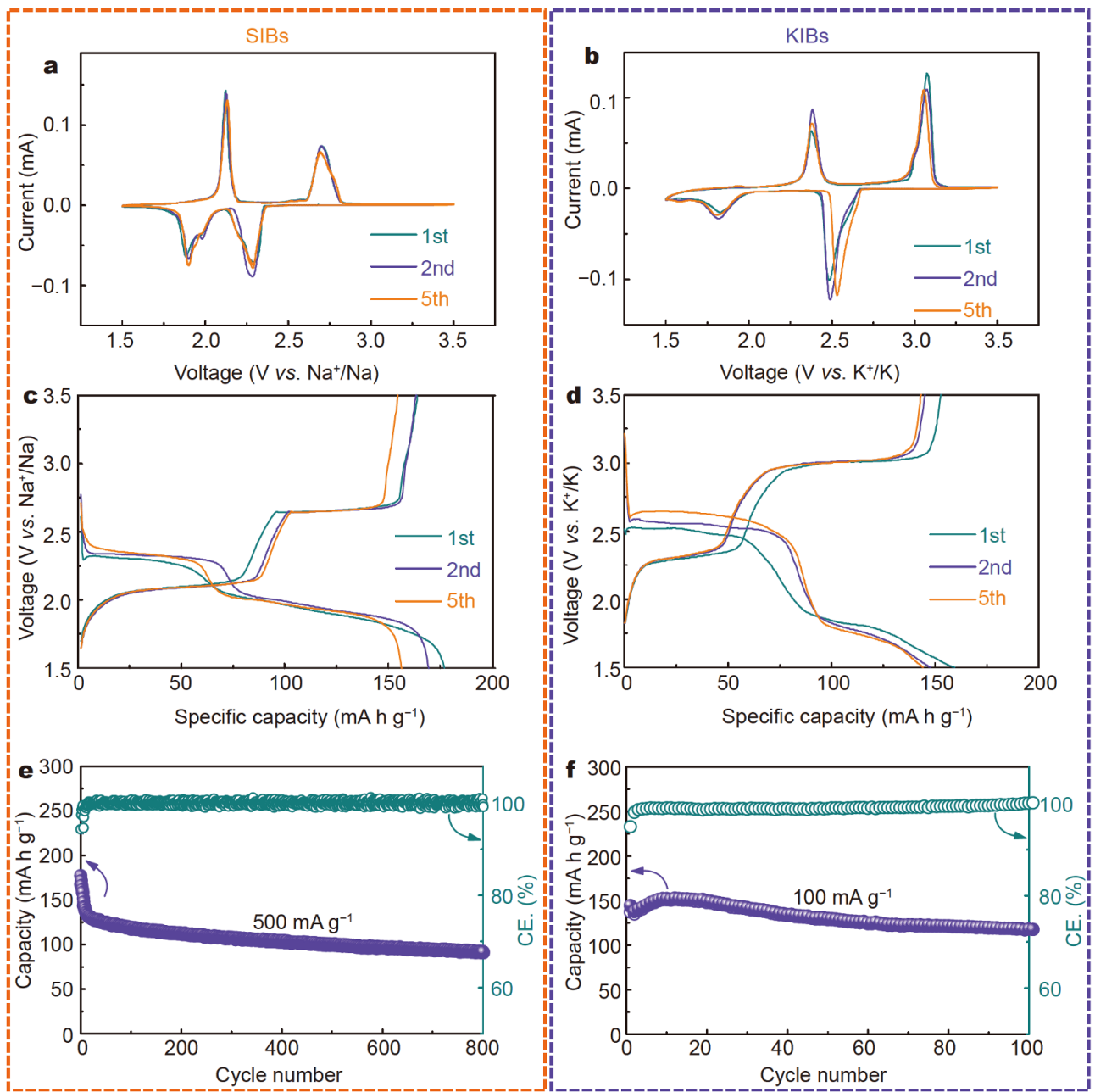

Figure 4 Electrochemical performance of the PNTCSA/RGO cathodes in SIBs and KIBs. (a, b) CV curves at $0.05 \mathrm{mV} \mathrm{s}^{-1}$. (c, d) Galvanostatic discharge-charge profiles at $100 \mathrm{~mA} \mathrm{~g}^{-1}$. (e, f) Cycling performance and CE at $500 \mathrm{~mA} \mathrm{~g}^{-1}$ in SIBs (the electrodes were activated at $100 \mathrm{~mA} \mathrm{~g}$ for 3 cycles) and $100 \mathrm{~mA} \mathrm{~g}^{-1}$ in KIBs. 
$0.05 \mathrm{mV} \mathrm{s}^{-1}$. As shown in Fig. 4a, b, PNTCSA/RGO exhibits two couples of redox peaks at $2.3 / 2.7 \mathrm{~V}$ and $1.8 / 2.15 \mathrm{~V}$ in SIBs, $2.5 / 3.05 \mathrm{~V}$ and $1.8 / 2.3 \mathrm{~V}$ in KIBs, respectively, corresponding to a two-step reversible reaction of carbonyls. This is different from the observations in LIBs (Fig. 3a). The reason may be associated with the kinetic difference in the insertion processes between $\mathrm{Na}^{+} /$ $\mathrm{K}^{+}$and $\mathrm{Li}^{+}$ions. Galvanostatic charge/discharge curves of PNTCSA/RGO for SIBs and KIBs in the selected cycles at a current density of $100 \mathrm{~mA} \mathrm{~g}^{-1}$ between 1.5 and $3.5 \mathrm{~V}$ are shown in Fig. 4c, d. In the first cycle, PNTCSA/RGO shows two plateaus at 2.3 and $1.8 \mathrm{~V}$ in SIBs and 2.5 and $1.8 \mathrm{~V}$ in KIBs, which are in accordance with those two redox couples in the CV curves. The initial CEs of PNTCSA/RGO cathode in SIBs and KIBs are $94.3 \%$ and 95\%, respectively, which are lower than that in LIBs.

The cycling performance of PNTCSA/RGO in SIBs were measured at $500 \mathrm{~mA} \mathrm{~g}^{-1}$, showing a long-term cycle life (Fig. 4e). The reversible capacities of 112.8, 103.6, and $92 \mathrm{~mA} \mathrm{~h} \mathrm{~g}^{-1}$ are retained after 200, 400, and 800 cycles, respectively. Remarkably, the $\mathrm{CE}$ is above $99.9 \%$, indicating good cycling stability and high reversibility of PNTCSA/RGO for $\mathrm{Na}^{+}$storage, which outperforms most reported PI-based cathode materials (Table S2). In addition, PNTCSA/RGO delivers a high reversible capacity of $117.9 \mathrm{~mA} \mathrm{~h} \mathrm{~g}^{-1}$ after 100 cycles at $100 \mathrm{~mA} \mathrm{~g}^{-1}$ in KIBs. The rate performance of the PNTCSA/RGO cathode in SIBs and KIBs at different galvanostatic current densities are shown in Fig. S7. When the current density increases from 100 to $1000 \mathrm{~mA} \mathrm{~g}^{-1}$, capacity retentions vary from 179.3 to $96.2 \mathrm{~mA} \mathrm{~h} \mathrm{~g}^{-1}$ in SIBs and from 165.9 to $115.7 \mathrm{~mA} \mathrm{~h} \mathrm{~g}^{-1}$ in KIBs, respectively, which are comparable to those in LIBs.

To investigate the reversibility of the crystal structure of PNTCSA during cycling, XRD measurement was performed at different discharged (lithiation, sodiation and potassiation) and charged (delithiation, desodiation and depotassiation) states. Fig. 5a shows the XRD patterns of the electrodes with pristine electrode as a reference. Strong characteristic peaks at $26.5^{\circ}$ and $28.1^{\circ}$ of PNTCSA are clearly observed in the pristine electrode. At discharged states, the XRD peaks become weak and broad but maintain the same position with those of pristine electrode, implying little change in crystal structure of PNTCSA and thereby little change in volume after AM ion insertion. Upon charging, pronounced peaks of the
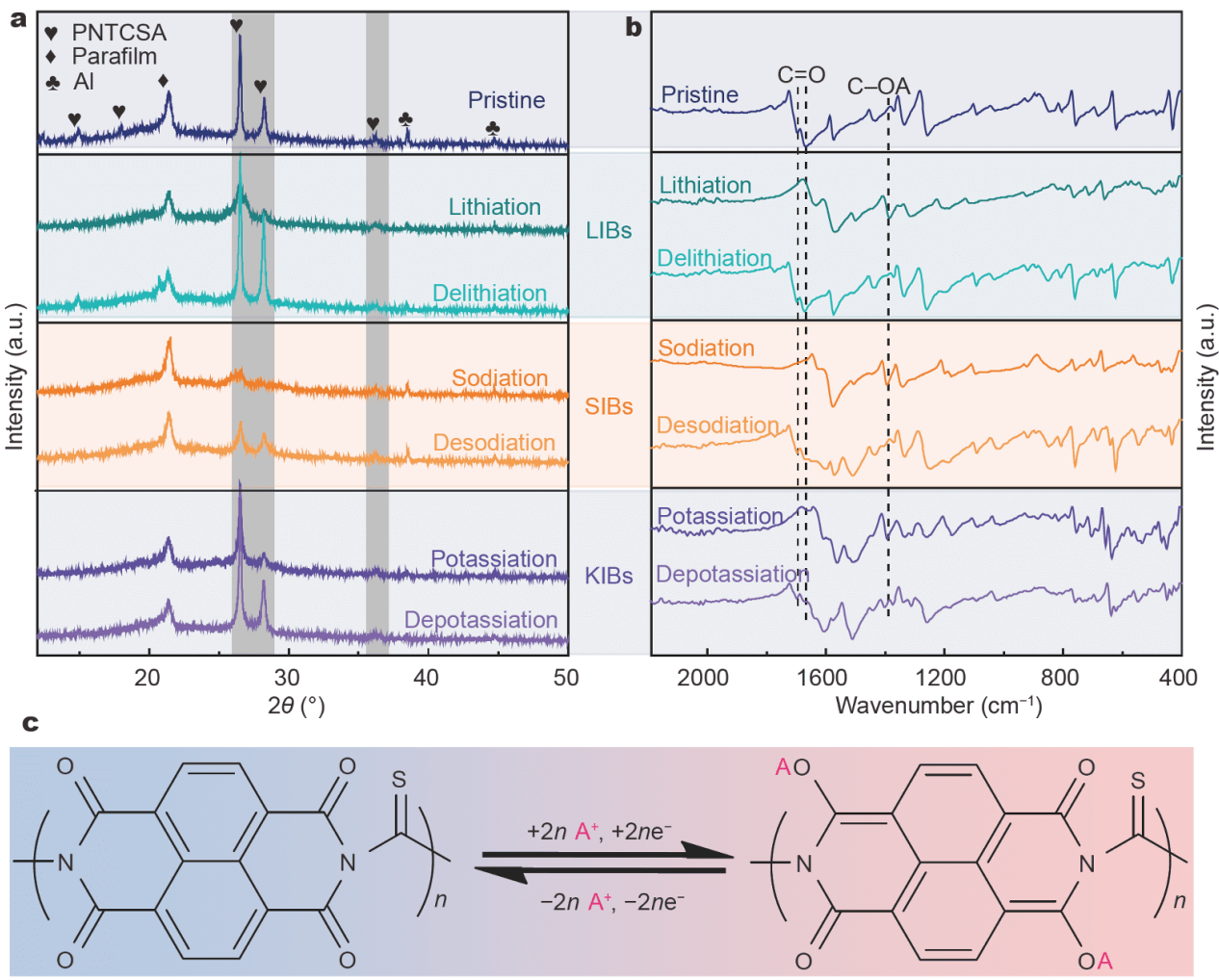

Figure 5 (a) XRD patterns and (b) FTIR spectra of the PNTCSA electrodes in different charged and discharged states in LIBs, SIBs and KIBs. (c) Schematic of the redox mechanism of the PNTCSA electrode when used as cathode materials for alkali ions storage $(A=L i, N a$, and K). 
pristine state are recovered, demonstrating a structure reversibility. This also accounts for the good cycling performance of PNTCSA.

To gain insight of the reaction mechanism of PNTCSA, the discharge/charge products in different AM ion battery systems were characterized by ex situ FTIR spectroscopy. All the spectra have been normalized for comparison. As shown in Fig. 5b, the stretching bands of $\mathrm{C}=\mathrm{O}$ located at $\sim 1696 \mathrm{~cm}^{-1}$ disappear at discharge state. Meanwhile, new peaks at $\sim 1388 \mathrm{~cm}^{-1}$ are observed, which are assigned to the enolate structure of $\mathrm{C}-\mathrm{OA}(\mathrm{A}=\mathrm{Li}, \mathrm{Na}$ and $\mathrm{K})$ [31]. These indicate that the $\mathrm{C}=\mathrm{O}$ bonds are reduced into $\mathrm{C}-\mathrm{OA}$ groups during the discharge process. During charge process, the $\mathrm{C}=\mathrm{O}$ band recovers and the newly formed C-OA bond vanishes. Therefore, the FTIR results show that $\mathrm{C}=\mathrm{O}$ bonds are active sites for $\mathrm{AM}$ ion storage. One PNTCSA unit can accept two AM ions and two electrons during the discharge process, corresponding to a theoretical capacity of $166 \mathrm{~mA} \mathrm{~h} \mathrm{~g}^{-1}$ (Fig. 5c).

To further investigate the charge/discharge mechanism of PNTCSA, DFT calculations were conducted. Two repeating units (denoted as NTCSA) in the polymer chains were selected as the calculation base and the dangling bonds were saturated with hydrogen atoms. The structures of NTCSA units are shown in Fig. 6a and Fig. S8. Sulfur atoms locate on two sides of the NTCSA unit plane, in which the dihedral angle of the end sulfur and the unit plane of NTCSA is $-11.52^{\circ}$, showing that two adjacent NTCSA units are not in the same plane. According to the FTIR results and previous reports, AM atoms are introduced into the PNTCSA chains through an enolization process: $\mathrm{C}=\mathrm{O} \rightarrow \mathrm{C}-\mathrm{O}-\mathrm{A}$. The calculation results reveal that one $A M$ atom is shared by two $C=O$ groups from two neighbor units. This is different from the previous reports on PI-based electrode materials, where one $\mathrm{AM}$ atom bonds with one $\mathrm{C}=\mathrm{O}$ group. One unit can accept one or two $\mathrm{AM}$ atoms, denoted as $\mathrm{AM}_{1}$ NTCSA or $\mathrm{AM}_{2}$-NTCSA, respectively (Fig. 6a). The average binding energies of different $\mathrm{AM}_{x}$-NTCSA compounds $(\Delta E)$ are in the range of -2.26 to $-3.60 \mathrm{eV}$, which
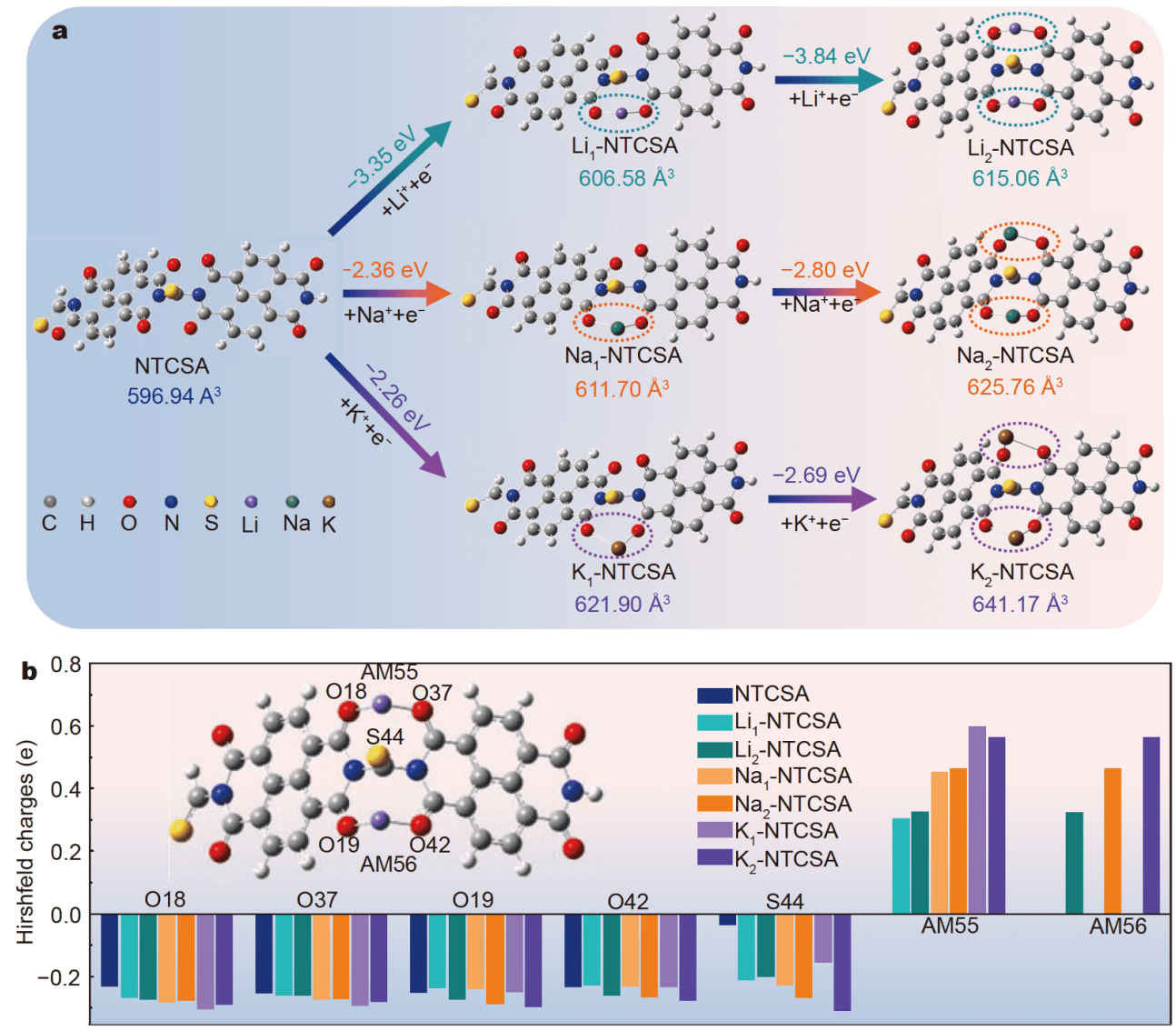

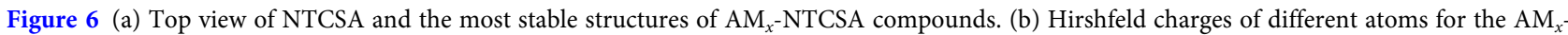
NTCSA compounds (insert in (b) is the selected unit of $\mathrm{AM}_{x}$-NTCSA for Hirshfeld charge analysis). 
are lower than that of previous PI-based electrode material, indicating the stronger binding between $\mathrm{AM}$ atoms and NTCSA (Table S3) [32]. Upon uptake of AM atoms, the NTCSA units show little volume expansion, $2.94 \%$ for $\mathrm{Li}, 4.61 \%$ for $\mathrm{Na}$ and $6.90 \%$ for $\mathrm{K}$, respectively (Table S3), which predicts high structure stability during charge/ discharge processes. This accounts for the excellent cycling stability of PNTCSA in LIBs. However, this is not consistent with the poor cycling performance of PNTCSA in KIBs.

To probe the performance difference of PNTCSA in LIBs, NIBs and KIBs, the charge transfer process was investigated by Hirshfeld charge analysis (Fig. 6b) [33]. The Hirshfeld charge analysis results for the uptake of one and two AM atoms are displayed in Fig. 6b. Given one AM atom is first accepted for one unit, charge values of O18, O37, and S44 atoms are higher than that of the pristine NTCSA, revealing a charge transfer from AM atoms to the nearby $\mathrm{O}$ and $\mathrm{S}$ atoms (Table S4). It is noted that the charges of $\mathrm{O} 18$ and $\mathrm{O} 37$ atoms for the uptake of $\mathrm{Li}$ and $\mathrm{Na}$ are smaller than that of $\mathrm{K}$, and the charges of $\mathrm{S} 44$ atoms are more negative when bonding to $\mathrm{Li}$ and $\mathrm{Na}$ than $\mathrm{K}$. These mean that the adsorption force between $\mathrm{O}$ atoms and $\mathrm{Li} / \mathrm{Na}$ ions are smaller than that between $\mathrm{O}$ atoms and $\mathrm{K}$ ions. After the uptake of the second $\mathrm{AM}$ atom for each unit, oxygen atoms of $\mathrm{O} 19$ and $\mathrm{O} 42$ get more negative charge, which leads to charge decrease of $\mathrm{O} 18$ and $\mathrm{O} 37$ atoms. The charge value decrease of $\mathrm{O} 18$ and $\mathrm{O} 37$ atoms is larger for $\mathrm{K}$ than those of $\mathrm{Na}$ and $\mathrm{Li}$, indicating that the binding interaction between $\mathrm{K}$ ions and $\mathrm{O}$ atoms is weaker. Meanwhile, sulfur atom of S44 gets more negative charge from $K_{1}$-NTCSA to $K_{2}$ NTCSA, suggesting that stronger interaction between $\mathrm{K}$ ions and $\mathrm{S}$ atoms than those between $\mathrm{Li} / \mathrm{Na}$ ions and $\mathrm{S}$ atoms. The strong $\mathrm{K}-\mathrm{S}$ and weak $\mathrm{K}-\mathrm{O}$ binding may cause poor structure reversibility, thus poor cycling stability (Figs 3g, 4e, 4f).

\section{CONCLUSIONS}

In summary, a novel thiourea-based PNTCSA/RGO composite has been designed and successfully synthesized through an in-situ polymerization strategy. Thanks to its strongly coupled and intriguing hybrid architecture, PNTCSA/RGO is proved to be suitable cathode material for AM ion storage. A high specific capacity of $144.2 \mathrm{~mA} \mathrm{~h} \mathrm{~g}^{-1}$, high discharge voltage of $2.5 \mathrm{~V}$, and long cycling life of 2000 cycles can be obtained in LIBs, which are comparable to those of other well documented inorganic electrodes. Moderate electrochemical performance is also obtained in SIBs and KIBs. The AM ion intercalation mechanisms in PNTCSA are elucidated by multiple characterization techniques, such as ex-situ FTIR, XRD and DFT calculations. More significantly, our work provides new insights in PI-based cathode materials for AM ion storage.

Received 3 March 2020; accepted 28 April 2020;

published online 19 June 2020

1 Winter M, Barnett B, Xu K. Before Li ion batteries. Chem Rev, 2018, 118: 11433-11456

2 Li M, Lu J, Chen Z, et al. 30 years of lithium-ion batteries. Adv Mater, 2018, 30: 1800561

3 Hwang JY, Myung ST, Sun YK. Sodium-ion batteries: present and future. Chem Soc Rev, 2017, 46: 3529-3614

4 Zou X, Xiong P, Zhao J, et al. Recent research progress in nonaqueous potassium-ion batteries. Phys Chem Chem Phys, 2017, 19: 26495-26506

5 Li L, Zheng Y, Zhang S, et al. Recent progress on sodium ion batteries: potential high-performance anodes. Energy Environ Sci, 2018, 11: 2310-2340

6 Hosaka T, Kubota K, Hameed AS, et al. Research development on K-ion batteries. Chem Rev, 2020, : acs.chemrev.9b00463

7 Schon TB, McAllister BT, Li PF, et al. The rise of organic electrode materials for energy storage. Chem Soc Rev, 2016, 45: 6345-6404

8 Zhao Q, Lu Y, Chen J. Advanced organic electrode materials for rechargeable sodium-ion batteries. Adv Energy Mater, 2017, 7: 1601792

9 Lu Y, Zhang Q, Li L, et al. Design strategies toward enhancing the performance of organic electrode materials in metal-ion batteries. Chem, 2018, 4: 2786-2813

10 Luo C, Ji X, Hou S, et al. Azo compounds derived from electrochemical reduction of nitro compounds for high performance Liion batteries. Adv Mater, 2018, 30: 1706498

11 Tie Z, Liu L, Deng S, et al. Proton insertion chemistry of a zincorganic battery. Angew Chem Int Ed, 2020, 59: 4920-4924

12 Wan F, Zhang L, Wang X, et al. An aqueous rechargeable zincorganic battery with hybrid mechanism. Adv Funct Mater, 2018, 28: 1804975

13 Luo C, Fan X, Ma Z, et al. Self-healing chemistry between organic material and binder for stable sodium-ion batteries. Chem, 2017, 3: 1050-1062

14 Shea JJ, Luo C. Organic electrode materials for metal ion batteries. ACS Appl Mater Interfaces, 2020, 12: 5361-5380

15 Häupler B, Wild A, Schubert US. Carbonyls: powerful organic materials for secondary batteries. Adv Energy Mater, 2015, 5: 1402034

16 Bhosale ME, Chae S, Kim JM, et al. Organic small molecules and polymers as an electrode material for rechargeable lithium ion batteries. J Mater Chem A, 2018, 6: 19885-19911

17 Xu Y, Zhou M, Lei Y. Organic materials for rechargeable sodiumion batteries. Mater Today, 2018, 21: 60-78

18 Muench S, Wild A, Friebe C, et al. Polymer-based organic batteries. Chem Rev, 2016, 116: 9438-9484

19 Song Z, Zhan H, Zhou Y. Polyimides: Promising energy-storage materials. Angew Chem Int Ed, 2010, 49: 8444-8448

20 Song Z, Xu T, Gordin ML, et al. Polymer-graphene nanocomposites as ultrafast-charge and -discharge cathodes for rechargeable lithium batteries. Nano Lett, 2012, 12: 2205-2211 
21 Huang Y, Li K, Liu J, et al. Three-dimensional graphene/polyimide composite-derived flexible high-performance organic cathode for rechargeable lithium and sodium batteries. J Mater Chem A, 2017, 5: $2710-2716$

22 Fan X, Wang F, Ji X, et al. A universal organic cathode for ultrafast lithium and multivalent metal batteries. Angew Chem Int Ed, 2018, 57: 7146-7150

23 Xu F, Xia J, Shi W, et al. Sulfonyl-based polyimide cathode for lithium and sodium secondary batteries: Enhancing the cycling performance by the electrolyte. Mater Chem Phys, 2016, 169: 192197

24 Chen C, Zhao X, Li HB, et al. Naphthalene-based polyimide derivatives as organic electrode materials for lithium-ion batteries. Electrochim Acta, 2017, 229: 387-395

25 Frisch M J, Clemente F R. Gaussian 09, Revision A. Gaussian, Inc., Wallingford CT, 2010

26 Sun MJ, Cao X, Cao Z. Stabilization of planar tetra-coordinate silicon in a 2D-layered extended system and design of a highcapacity anode material for Li-ion batteries. Nanoscale, 2018, 10 : 10450-10458

27 Lu T, Chen F. Multiwfn: a multifunctional wavefunction analyzer. J Comput Chem, 2012, 33: 580-592

28 Sharma P, Damien D, Nagarajan K, et al. Perylene-polyimidebased organic electrode materials for rechargeable lithium batteries. J Phys Chem Lett, 2013, 4: 3192-3197

29 Marvel CS, de Radzitzky P, Brader JJ. An improved preparation of dithioesters and some reactions and spectral properties of these compounds. J Am Chem Soc, 1955, 77: 5997-5999

$30 \mathrm{Wu} \mathrm{H}$, Wang K, Meng Y, et al. An organic cathode material based on a polyimide/CNT nanocomposite for lithium ion batteries. J Mater Chem A, 2013, 1: 6366-6372

31 Armand M, Grugeon S, Vezin $\mathrm{H}$, et al. Conjugated dicarboxylate anodes for Li-ion batteries. Nat Mater, 2009, 8: 120-125

32 Wang J, Li F, Qu Y, et al. PNTCDA: a promising versatile organic electrode material for alkali-metal ion batteries. J Mater Chem A, 2018, 6: 24869-24876

33 Zhang Z, Zhang Y, Li Y, et al. $\mathrm{MnSb}_{2} \mathrm{~S}_{4}$ monolayer as an anode material for metal-ion batteries. Chem Mater, 2018, 30: 3208-3214

Acknowledgements This work was financially supported by the National Natural Science Foundation of China (51672188 and 21703036).

Author contributions Xiong $\mathrm{P}$ and $\mathrm{Xu} \mathrm{Y}$ designed the project; Xiong $\mathrm{P}$ performed the main experiments; $\mathrm{Yin} \mathrm{H}$ and Huang $\mathrm{S}$ conducted the theoretical calculation; Chen Z, Zhao C and Yang J helped with the experiments and analyses; Xiong $\mathrm{P}$ wrote the manuscript with support from Xu Y. All authors participated in the manuscript revision.

Conflict of interest The authors declare no conflict of interest.

Supplementary information online version of the paper.

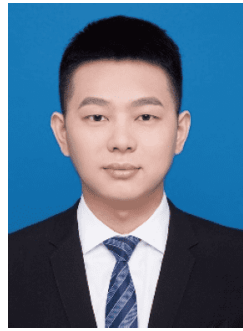

Peixun Xiong received his BSc and MSc degree from Fuzhou University in 2013 and 2016, respectively. $\mathrm{He}$ is now a $\mathrm{PhD}$ candidate under the supervision of Prof. Yunhua Xu at the School of Materials Science and Engineering, Tianjin University. His current research mainly focuses on the synthesis and characterization of nanomaterials for electrochemical energy storage devices.

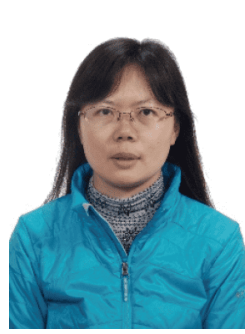

Shuping Huang obtained her $\mathrm{PhD}$ degree in physical chemistry at Fujian Institute of Research on the Structure of Matter, Chinese Academy of Sciences in 2008. She joined Prof. Ruiqin Zhang's group as a research fellow in CityU. She was awarded JSPS fellowship and hosted by Prof. Kazunari Yoshizawa at Kyushu University in 2010-2012. She continued her postdoctoral research at University of South Dakota with Prof. Dmitri Kilin and at University of Minnesota with Prof. Donald Truhlar from 2013-2016. She is currently a professor at Fuzhou University. Her research is focused on energy materials.

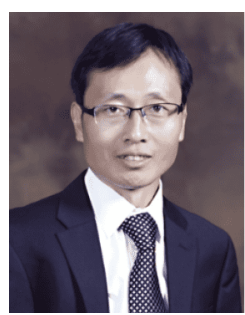

Yunhua Xu is a professor at the School of Materials Science and Engineering, Tianjin University. He received his $\mathrm{PhD}$ degree in materials physics and chemistry from South China University of Technology in 2008. Prior to joining Tianjin University, he worked as a visiting student and postdoc at the University of California, Santa Barbara and assistant research scientist at the University of Maryland, College Park from 2006 to 2015. His research interests focus on electrochemical storage materials and devices.

\section{硫脲基聚酰亚胺/还原氧化石墨烯复合正极：碱金 属离子储存机理的综合研究}

熊佩勋 ${ }^{1}$, 尹慧敏 $^{2}$, 陈子峰 $^{1}$, 赵晨 $^{1}$, 杨继兴 ${ }^{1}, \mathbf{M}^{\text {淑萍 }}{ }^{2 *}$, 许运华 ${ }^{1,}$

摘要 尽管有机电极材料具有资源丰富、结构多样及环境友好等 特点, 但是它们的电化学性能仍然不理想. 本文通过缩聚法合成了 一种硫艮基聚酰亚胺/还原氧化石墨烯复合物. 当其作为正极材料 应用于锂离子电池时, 展现出优异的电化学性能, 如高可逆比容量 (144.2 $\mathrm{mA} \mathrm{h} \mathrm{g}^{-1}$ ), 高放电电压 $(2.5 \mathrm{~V})$ 和长循环寿命(在 $500 \mathrm{~mA} \mathrm{~g}^{-1}$ 电流密度下超过 2000 次), 可以和其他发展较好的无机正极材料相 媲美. 当其作为正极材料应用于钠离子电池时, 也可获得较好的电 化学性能(在 $500 \mathrm{~mA} \mathrm{~g}^{-1}$ 电流密度下循环寿命达 800 次), 但是作为钾 离子电池正极材料时的性能较差. 理论计算表明羰基是和三种碱 金属离子结合的活性位点，且插入的金属离子被邻位的两个羰基 共用. 更重要的是, 硫原子和钾之间的作用力要远远大于和锂/钠 之间的作用力, 使得该聚合物在钾离子电池中表现出较差的可逆 性和循环稳定性. 我们的发现不仅为聚酰亚胺基的聚合物电极的 设计和开发提供了理论基础，同时也为高性能的碱金属离子电池 有机电极材料的设计和开发提供了帮助. 